Check for updates

Cite this: RSC Adv., 2021, 11, 19737

\title{
N/O co-enriched graphene hydrogels as high- performance electrodes for aqueous symmetric supercapacitors $\dagger$
}

\begin{abstract}
Yong Zhang, (D)*ac Liang Wei, ${ }^{\text {ac }}$ Xijun Liu, ${ }^{\text {ac }}$ Wenhui Ma, ${ }^{\text {b }}$ Jiankai Wang ${ }^{\text {b }}$ and Shan Fan*ac

In this study, an easy one-pot hydrothermal strategy was used to prepare N/O co-enriched graphene hydrogels (NOGHs) using graphene oxide (GO) solution and $n$-propylamine as a reactant. The $n$ propylamine can be used not only as a reductant, nitrogen dopant and structure regulator, but also as a spacer to inhibit the agglomeration of graphene sheets. Benefiting from the synergistic effect between the heteroatoms ( $N, \mathrm{O}), 3 \mathrm{D}$ porous structures and high specific surface area, the as-prepared NOGH samples present excellent electrochemical properties. Remarkably, the NOGH-140 based binder-free symmetric supercapacitor shows a high specific capacitance of $268.1 \mathrm{~F} \mathrm{~g}^{-1}$ at the current density of $0.3 \mathrm{~A} \mathrm{~g}^{-1}$ and retains $222.5 \mathrm{~F} \mathrm{~g}^{-1}$ (82.9\% of its initial value) at $10.0 \mathrm{~A} \mathrm{~g}^{-1}$ in $6 \mathrm{M} \mathrm{KOH}$ electrolyte. Furthermore, the assembled device also displays a notable energy density $\left(9.3 \mathrm{~W} \mathrm{~h} \mathrm{~kg}^{-1}\right)$ and outstanding cycling performance ( $1.8 \%$ increase of its initial specific capacitance after 10000 cycles at $10 \mathrm{~A} \mathrm{~g}^{-1}$ ). The simple preparation method and excellent electrochemical properties indicate that NOGHs can be used as electrode materials for commercial supercapacitors.
\end{abstract}

\begin{abstract}
Received 9th March 2021 Accepted 23rd May 2021 DOI: 10.1039/d1ra01863a rsc.li/rsc-advances
\end{abstract}

materials for supercapacitors due to their high specific surface area and excellent physicochemical stability. ${ }^{\mathbf{1 1 2} 12}$ However, carbon-based electrode materials mainly produce electric double layer capacitance (EDLC), which greatly reduces the energy density of the device and thus limits its practical application. In order to improve the energy density of supercapacitors, many studies have focused on the electrode materials of traditional batteries (transition metal oxides, conductive polymers). These electrode materials can produce substantial pseudocapacitances with the help of Faraday reaction, which is very in line with the requirements of batteries for high energy density. However, when used as electrode materials for supercapacitors, the poor rate capability of these materials cannot support the high current charging and discharging, and their poor reversible Faraday reaction makes them can only use for a few thousands charge and discharge cycles, which completely cannot meet the requirements of supercapacitor for ultrahigh service life. ${ }^{\mathbf{1 3}, 14}$ Therefore, more and more researchers have refocused on carbon-based electrode materials.

Graphene oxide can be regarded as oxygen-doped graphene materials, and its surface contains plenty of different types of oxygen-containing functional groups. Except for epoxy functional groups, the other oxygen-containing functional groups (carboxyl, carbonyl and hydroxyl) can enhance the wettability of electrode materials and generate abundant pseudocapacitances to enhance their energy density. ${ }^{15-17}$ However, the low conductivity and high epoxy functional group content of GO severely restrict its application in electrochemical field. At present, many 
studies have used high-temperature reduction method to solve this problem, which not only consumes a lot of energy but also causes irreparable damage to the sheet structure of graphene. In addition, the agglomeration problem that occurs during the preparation of graphene will greatly reduce its specific surface area and block the transmission channel of electrolyte ions, which seriously limits the application of graphene as electrode materials.

Based on the above reasons, we believe that graphene-based electrode materials can be prepared by hydrothermal reaction of GO with organic amine molecules. ${ }^{\mathbf{1 8 - 2 0}}$ Firstly, the relatively mild reaction conditions in the hydrothermal process can maximize the retention of oxygen on the surface of graphene sheets. Furthermore, one epoxy functional group will react with water molecules under hydrothermal conditions to decompose into two hydroxyl functional groups, which will further boost the electrochemical properties of the material. Secondly, the amino functional group in the organic amine molecule can adjust the sheet structure of graphene by nitrogen doping, thus improving its electrical conductivity. Thirdly, the molecular chain of organic amines will anchor on the graphene sheets with the help of nitrogen doping, which can effectively prevent the agglomeration between adjacent graphene sheets and enlarge the specific surface area utilization rate. Finally, the resulting $\mathrm{N}$ and $\mathrm{O}$ enriched graphene materials will possess good pseudocapacitance behaviors and favourable wettability.

To demonstrate that, we utilized a one-pot hydrothermal approach to prepare N/O co-enriched graphene hydrogels (NOGHs) using GO and $n$-propylamine as reactant. During the preparation process, $n$-propylamine can be used not only as reductant, nitrogen dopant and structure regulator but also as physical spacer to inhibit the agglomeration of graphene sheets (Scheme 1). Due to the 3D porous structures, synergistic effect between the heteroatoms ( $\mathrm{N}, \mathrm{O})$ and high specific surface, the as-prepared NOGHs samples present a high specific capacitance and exceptional cycling stability. In view of the simple and efficient preparation method and the excellent electrochemical properties, we believe that NOGHs can be used as electrode materials for commercial supercapacitors.

\section{Experimental}

\subsection{Preparation of NOGHs}

GO was prepared according to a previous report. ${ }^{21}$ NOGHs were prepared by a one-pot hydrothermal. First, $n$-propylamine $(70$, 140 or $210 \mu \mathrm{L}$ ) was added into $70 \mathrm{~mL}$ of $2.5 \mathrm{mg} \mathrm{mL}^{-1} \mathrm{GO}$ solution. After stirring for $0.5 \mathrm{~h}$, the mixed aqueous was transferred to a hydrothermal synthesis reactor and treated at $180{ }^{\circ} \mathrm{C}$ for $12 \mathrm{~h}$ and cooled to room temperature. Then, the obtained hydrogel was taken out and washed with deionized water scrupulously to eliminate unreacted $n$-propylamine. Finally, the hydrogel was collected and dried by freeze-drying. The NOGH70, NOGH-140 and NOGH-210 were nominated built upon the volume of $n$-propylamine. For comparison, graphene hydrogel (GH) was also prepared by the same process without adding any $n$-propylamine.

\subsection{Instrumentation and characterisation}

The samples were characterized by X-ray diffraction (XRD, DX2700 diffractometer with $\mathrm{Cu} \mathrm{K} \alpha$ radiation), Raman spectrometer (Invia Raman microscope), Fourier transform infrared spectra (FTIR, AVATAR-370 spectrometer), X-ray photoelectron spectroscopy (XPS, ESCALAB 250Xi spectrometer), $\mathrm{N}_{2}$ sorption isotherms (3H-2000PS1), scanning electron microscopy (SEM, Hitachi S-4300), and transmission electron microscope (TEM, JEM-2100). All samples used for characterization are freezedried powders.

\subsection{Electrochemical measurement}

All supercapacitors properties were measured by using a $\mathrm{CHI}$ $760 \mathrm{E}$ electrochemical workstation in $6 \mathrm{M} \mathrm{KOH}$ electrolyte. To prepare the working electrode, a slice of the as-prepared hydrogel was directly pressed onto nickel foam and maintained at $10 \mathrm{MPa}$ pressure for $30 \mathrm{~s}$. Subsequently, two working electrodes with almost the same mass of active materials are separated by a cellulose separator and packaged into a CR2025 coin-type cell. Cyclic voltammetry (CV) was measured under different scan rates of 5 to $100 \mathrm{mV} \mathrm{s}^{-1}$, and galvanostatic charge/discharge (GCD) test was measured from 0 to $1 \mathrm{~V}$ at various current densities of 0.3 to $10 \mathrm{~A} \mathrm{~g}^{-1}$. The electrochemical impedance spectroscopy (EIS) was performed at $5 \mathrm{mV}$ amplitude over the frequency range of 0.01 to $10^{5} \mathrm{~Hz}$.

The specific capacitances $\left(C_{\mathrm{s}}, \mathrm{F} \mathrm{\textrm {g } ^ { - 1 }}\right)$ of the binder-free symmetric supercapacitors were obtained from the GCD process according to the following formula:

$$
C_{\mathrm{s}}=2(I \times \Delta t / m \times \Delta V)
$$

where $I, \Delta t, m$ and $\Delta V$ stand for the applied current (A), discharge time (s), mass in a single electrode $(\mathrm{g})$ and usable voltage after the $I R$ drop $(\mathrm{V})$, respectively.

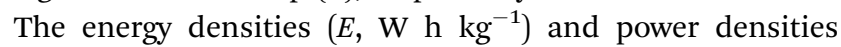
$\left(P, \mathrm{~W} \mathrm{~kg}^{-1}\right)$ of the binder-free symmetric supercapacitors were derived for the GCD tests based on the following formula:

$$
\begin{gathered}
E=C_{\mathrm{s}} \Delta V^{2} / 8 \\
P=E / \Delta t
\end{gathered}
$$

where $C_{\mathrm{s}}$ represents the specific capacitance of the symmetric supercapacitors, $\Delta t$ is the discharge time (s), and $\Delta V$ is the usable voltage after the $I R$ drop $(\mathrm{V})$.

\section{Results and discussion}

\subsection{Material characteristic}

XRD patterns were implemented to depict the crystallinity and amorphous nature of all samples. As seen from Fig. 1a, the diffraction peak of the (002) plane for GO centered at $12.4^{\circ}$ disappeared after the hydrothermal reaction, denoting the partial reduction of GO. The weak and broad characteristic peaks at approximately $21-26^{\circ}$ in GH and NOGHs samples indicate the restacking of graphene sheets and their amorphous structures. $^{22}$ Obviously, the broad characteristic peaks in 


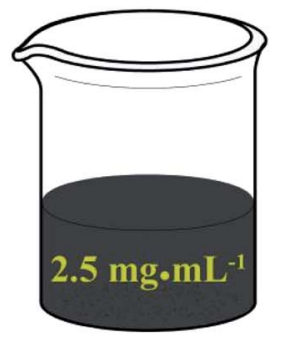

GO

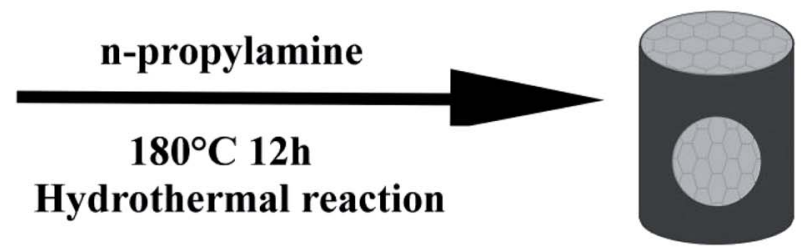

NOGHs
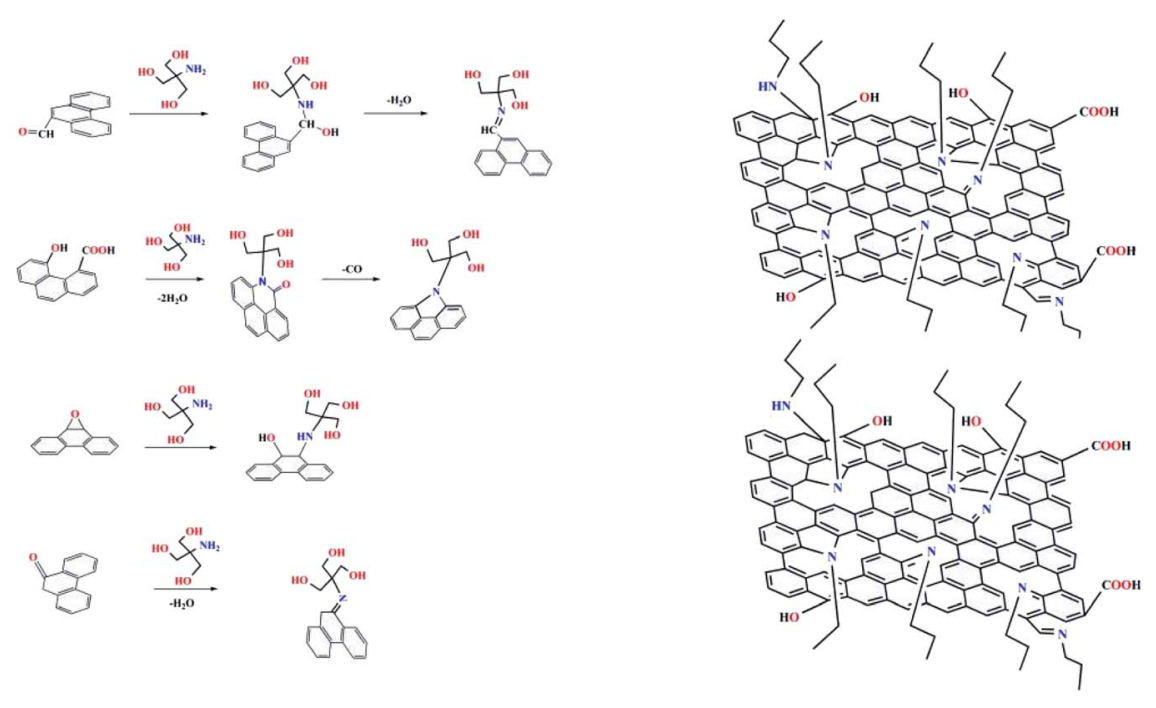

Scheme 1 Illustration of the possible reaction mechanism of the NOGHs.

NOGHs are downshifted than that of GH, which can be ascribed to the increased interlayer distance of graphene sheets as a result of the supporting effect of $n$-propylamine molecular chains. The increase of interlayer distance can accelerate the transport of both electrons and electrolyte ions in the electrode materials. ${ }^{23}$ Furthermore, the FWHM of (002) peaks of NOGHs is obvious larger compare to that of $\mathrm{GH}$, suggesting their more disorder stacking structure (Table 1).

Raman spectra were used to characterize the structure and defect of all samples. As depicted in Fig. 1b, all samples clearly display two characteristic bands at around 1345 and $1594 \mathrm{~cm}^{-1}$, which correspond to the $\mathrm{D}$ and $\mathrm{G}$ band, respectively. $\mathrm{D}$ band is ascribed to the in-plane substitutional heteroatoms or defects in the graphene sheets. In contrast, $\mathrm{G}$ band refers to the $\mathrm{sp}^{2}$ hybridized graphitic domains. The D bands and $\mathrm{G}$ bands of NOGHs display downshift in comparison with those of GO and $\mathrm{GH}$, which is due to the nitrogen doping. ${ }^{24,25}$ The ratio of $\mathrm{D}$ band and $\mathrm{G}$ band $\left(I_{\mathrm{D}} / I_{\mathrm{G}}\right)$ is employed to characterize the disorders and defects of graphene-based materials. Evidently, the $I_{\mathrm{D}} / I_{\mathrm{G}}$ of NOGHs is larger than that of $\mathrm{GH}$, demonstrating their higher defect degree due to the heteroatom doping. ${ }^{26}$ These defects can not only provide new sites for the adsorption of the electrolyte, but also play a catalytic role in Faraday redox reaction, which can greatly improve the capacitive property of the materials. Furthermore, the higher $I_{\mathrm{D}} / I_{\mathrm{G}}$ value in NOGHs can also manifest the transformation of $\mathrm{sp}^{3}$ carbon to $\mathrm{sp}^{2}$ carbon during the
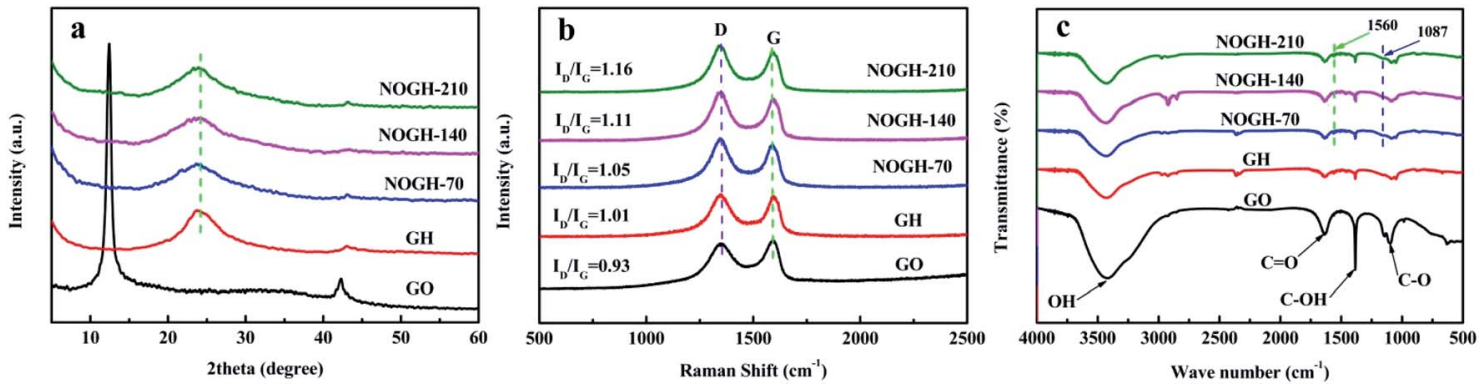

Fig. 1 (a) XRD, (b) Raman and (c) FTIR of all samples. 
Table 1 XRD data, Raman peaks and conductivity of samples

\begin{tabular}{llllll}
\hline Sample & $\begin{array}{l}\text { 2 Theta } \\
\left({ }^{\circ}\right)\end{array}$ & FWHM & $\begin{array}{l}\text { D-band peak } \\
\left(\mathrm{cm}^{-1}\right)\end{array}$ & $\begin{array}{l}\text { G-band peak } \\
\left(\mathrm{cm}^{-1}\right)\end{array}$ & $\begin{array}{l}\sigma \\
\left(\mathrm{S} \mathrm{m}^{-1}\right)\end{array}$ \\
\hline GO & 12.40 & 0.522 & 1352.48 & 1592.77 & - \\
GH & 24.25 & 4.375 & 1349.21 & 1593.02 & 158 \\
NOGH-70 & 23.87 & 4.551 & 1347.58 & 1587.76 & 323 \\
NOGH-140 & 23.80 & 4.794 & 1346.79 & 1591.45 & 357 \\
NOGH-210 & 23.73 & 4.799 & 1345.39 & 1589.81 & 354 \\
\hline
\end{tabular}

hydrothermal process, which will boost their electric conductivity.

FT-IR spectra were used to analyse the functional groups and verify the successful reaction of $n$-propylamine with GO. As shown in Fig. 1c, the GO spectrum displays several peaks at about $3421 \mathrm{~cm}^{-1}, 1635 \mathrm{~cm}^{-1}, 1384 \mathrm{~cm}^{-1}$ and $1089 \mathrm{~cm}^{-1}$ correspond to the stretching vibration of $\mathrm{O}-\mathrm{H}$ in physisorbed water or carboxylate moieties, $\mathrm{C}=\mathrm{O}$ in carboxylic acid, $\mathrm{C}-\mathrm{OH}$ and $\mathrm{C}-\mathrm{O}$, respectively, denoting the presence of massive oxygencontaining functional groups. ${ }^{27}$ Compared with GO, in the spectra of GH and NOGHs, the characteristic peaks of these oxygen-containing functional groups are significantly weakened, indicating that GO is partially reduced. Meanwhile, there are two new peaks at $1560 \mathrm{~cm}^{-1}$ and $1087 \mathrm{~cm}^{-1}$ in the spectra of NOGHs corresponding to the stretching vibrations of $\mathrm{C}=\mathrm{N}$ (Fig. $\mathrm{S} 1 \dagger$ ) and $\mathrm{C}-\mathrm{N}$ bonds (Fig. $\mathrm{S} 2 \dagger$ ), confirming the effective doping of $\mathrm{N}$ into the graphene lattice. ${ }^{28}$ As a result of all this, we believe that with the success of nitrogen doping, the molecular chain of $n$-propylamine has been anchored on the graphene surface. These molecular chains can be used as spacer to restrain the agglomeration of graphene sheets, thereby improving the porous structure of the sample and increasing its specific surface area utilization (Scheme 1).

XPS measurement was carried out to probe the elemental compositions and the bonding configurations of $\mathrm{O}$ and $\mathrm{N}$ of all samples. As exhibited in Fig. 2a, the XPS survey spectrum of GO presents strong signals of the $\mathrm{C} 1 \mathrm{~s}$ and $\mathrm{O} 1 \mathrm{~s}$ peaks, demonstrating the presence of abundant oxygen-containing functional groups on the surface of GO. ${ }^{29}$ However, the relative intensity of $O$ 1s peak decreased significantly after the hydrothermal process, denoting the partial reduction of GO. The XPS survey spectra of NOGHs show a distinct $\mathrm{N}$ 1s peak, which indicates the successful incorporation of $\mathrm{N}$ into the graphene matrix. In addition, the appearance of $\mathrm{C}=\mathrm{N}$ and $\mathrm{C}-\mathrm{N}$ signals in the highresolution C 1s spectra of NOGH-140 (Fig. 2b) further proves the success of nitrogen doping. Moreover, the atomic percentage of $\mathrm{C}, \mathrm{N}$ and $\mathrm{O}$ atoms of all samples are depicted in Table 2. As shown in Fig. 2c, the high-resolution $\mathrm{N}$ 1s XPS spectrum of NOGH-140 can be fitted into four peaks centered at about 398.7, 399.9, 400.7 and $402.1 \mathrm{eV}$, which are due to the $\mathrm{N}$ binding configurations of pyridinic $\mathrm{N}$, pyrrolic $\mathrm{N}, \mathrm{N}-\mathrm{H}$ band and graphitic $\mathrm{N}$, respectively. This indicates that after nucleophilic substitution reaction with oxygen-containing functional groups on GO surface, the nitrogen atoms are successfully bonded to the carbon atoms in the graphene lattice through covalent bonds. The existence of these covalent bonds can enhance the electronic properties of graphene, increase the dispersion of graphene sheets, and also boost the interface interaction between graphene and the matrix. ${ }^{30}$ Notably, pyridinic $\mathrm{N}$ can improve the absorption and diffusion capacity of electrolyte ions inside the electrode material, thereby improving their capacitive property and rate capability. Meanwhile, pyrrolic $\mathrm{N}$ can generate lots of vacancies and defects in NOGHs, which will effectively enhance the electrochemical behaviors of NOGHs by
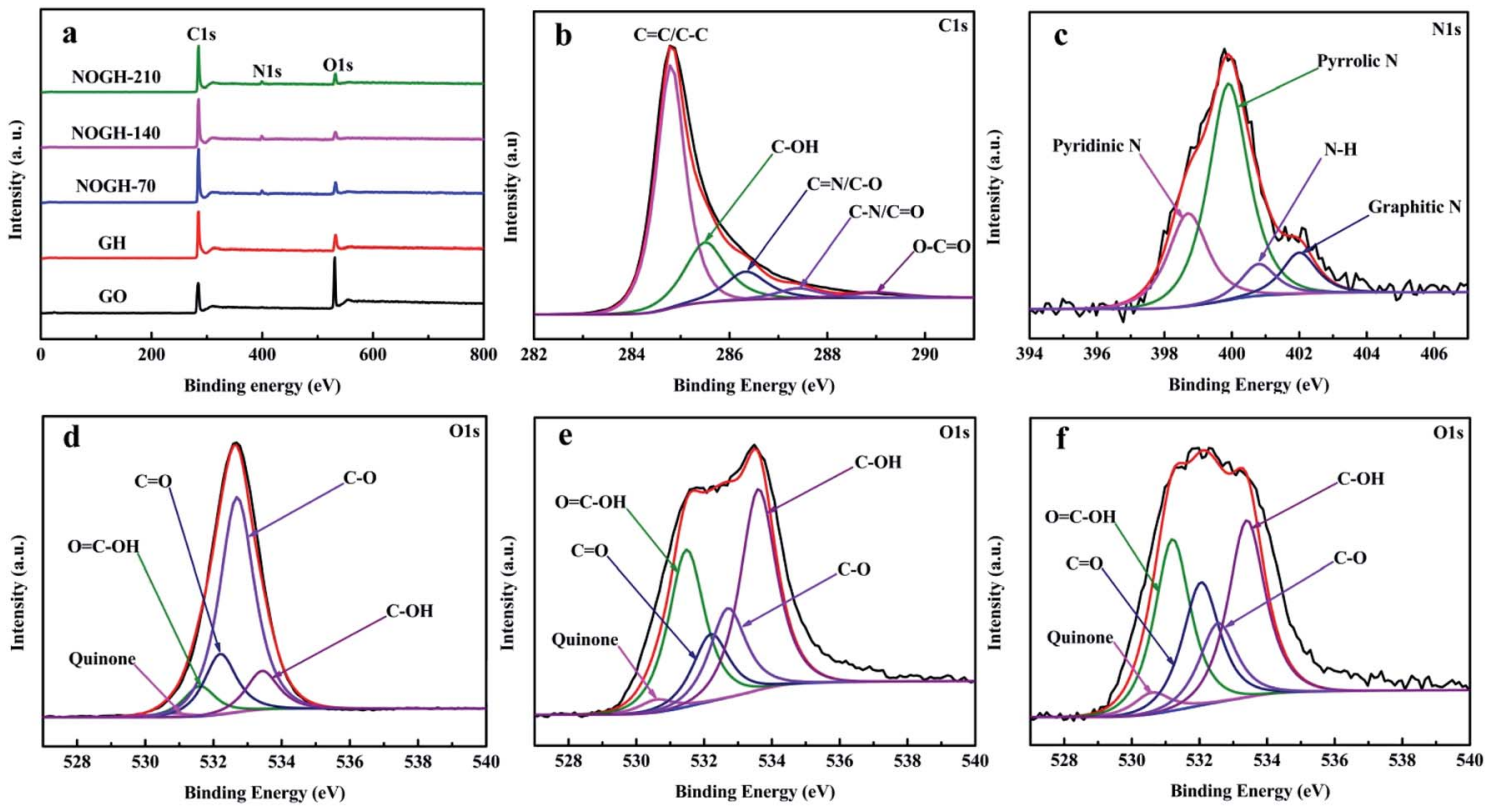

Fig. 2 (a) XPS survey spectra of all samples, (b) C 1s and (c) N 1s XPS spectra of NOGH-140. O 1s XPS spectra of (d) GO, (e) GH and (f) NOGH-140. 
Table 2 The elemental contents and quantitative analysis of O 1s XPS data of GO, GH and NOGHs (at\%)

\begin{tabular}{|c|c|c|c|c|c|c|c|c|c|}
\hline Samples & $\mathrm{C}$ & $\mathrm{O}$ & $\mathrm{N}$ & Quinone & $\mathrm{COOH}$ & $\mathrm{C}=\mathrm{O}$ & $\mathrm{C}-\mathrm{O}$ & $\mathrm{C}-\mathrm{OH}$ & $\mathrm{C} / \mathrm{O}$ \\
\hline GO & 67.85 & 32.15 & - & 0.38 & 2.64 & 5.30 & 20.45 & 3.38 & 2.11 \\
\hline $\mathrm{GH}$ & 86.17 & 13.83 & - & 0.32 & 4.26 & 1.74 & 2.31 & 5.20 & 6.23 \\
\hline NOGH-70 & 87.04 & 9.51 & 3.45 & 0.32 & 2.43 & 2.33 & 1.41 & 3.02 & 9.15 \\
\hline NOGH-140 & 88.02 & 7.31 & 4.67 & 0.27 & 2.16 & 1.59 & 1.02 & 2.27 & 12.04 \\
\hline NOGH-210 & 85.22 & 9.14 & 5.64 & 0.20 & 2.30 & 1.90 & 1.13 & 3.61 & 9.32 \\
\hline
\end{tabular}

its fast kinetics and reversibly binding with the charge carriers. ${ }^{31}$ Additionally, graphitic $\mathrm{N}$ can not only catalyze the pseudocapacitance reaction, but also improve the conductivity of NOGHs by restoring the conjugation of graphene sheet.

Fig. 2d-f compare the $\mathrm{O}$ 1s XPS spectra of GO, GH and NOGH-140. It can be seen that these $\mathrm{O} 1 \mathrm{~s}$ spectra can be fitted into five peaks at about $530.6 \mathrm{eV}, 531.5 \mathrm{eV}, 532.1 \mathrm{eV}, 532.7 \mathrm{eV}$ and $533.5 \mathrm{eV}$, corresponding to quinone $\mathrm{O}, \mathrm{O}=\mathrm{C}-\mathrm{OH}, \mathrm{C}=\mathrm{O}$, $\mathrm{C}-\mathrm{O}$ and $\mathrm{C}-\mathrm{OH}$ functionalities, respectively. In addition, with the increase in the amount of $n$-propylamine, the nitrogen content in NOGHs samples gradually increased while the oxygen content generally decreased. Most importantly, the content of epoxy functional groups in these samples decreased gradually with the addition of $n$-propylamine, which could be attributed to the ring-opening reaction between the epoxy functional groups and water molecules and the nucleophilic substitution reaction between $n$-propylamine and epoxy functional groups under hydrothermal conditions (Table 2). These retained oxygen-containing functional groups can substantially increase the active reaction sites of the materials and boost their pseudocapacitance. Furthermore, these oxygen-containing functional groups can also improve the wettability of the NOGHs and reduce their inert surface area, thereby increasing the infiltration of NOGHs and promoting the transport of electrolyte ions. ${ }^{32}$ The above results indicate that the $n$-propylamine molecule realizes the functionalization of the graphene sheet through the covalent bond, which will greatly improve the porous structure and surface chemistry of the NOGH samples, thereby enhancing their electrochemical performance.
The specific surface area and pore structures of GH and NOGH-140 were acquired by $\mathrm{N}_{2}$ adsorption/desorption isotherms, as illustrated in Fig. 3. It is clear that both GH and NOGH-140 display IV-type curves with obvious hysteresis loops at $P / P_{0}$ of $0.4-1.0$, denoting the coexistence of mesopores and macropores structures. Moreover, the isotherm of NOGH-140 shows an almost vertical $\mathrm{N}_{2}$ uptakes below $0.02 P / P_{0}$, indicating the presence of micropores. The pore size distribution of $\mathrm{GH}$ and NOGH-140 further proves the above results (inset in Fig. 3). The dominant pore volume of the NOGH-140 is mesopores (3-4 nm, 20-50 nm) and macropores (50-100 nm). This porous structure can provide more internal channels for the transmission of electrolyte ions, thereby boosting the capacitive property and rate capability of the sample. Meanwhile, NOGH140 also has some micropores below $2 \mathrm{~nm}$, which is conducive to the generation of EDLC capacitance. ${ }^{26}$

Moreover, the micropore volume of NOGH-140 is about 2 times than that of $\mathrm{GH}$, which is because the oxygen-containing functional groups on GO surface are easier to decomposition during the hydrothermal reaction with $n$-propylamine. The specific surface area of GH is only $116.2 \mathrm{~m}^{2} \mathrm{~g}^{-1}$. On the contrary, the specific surface area of NOGH-140 drastically increases to $237.7 \mathrm{~m}^{2} \mathrm{~g}^{-1}$, which suggests that the addition of $n$-propylamine can effectively regulate the specific surface area of the sample. The improved specific surface area of NOGH-140 can deliver more places for the adsorption/desorption of electrolyte ions and electrochemical reactions, and then improve its electrochemical performance. ${ }^{33}$ Moreover, the total pore volume of NOGH-140 is $0.42 \mathrm{~cm}^{3} \mathrm{~g}^{-1}$, larger than that of $\mathrm{GH}$
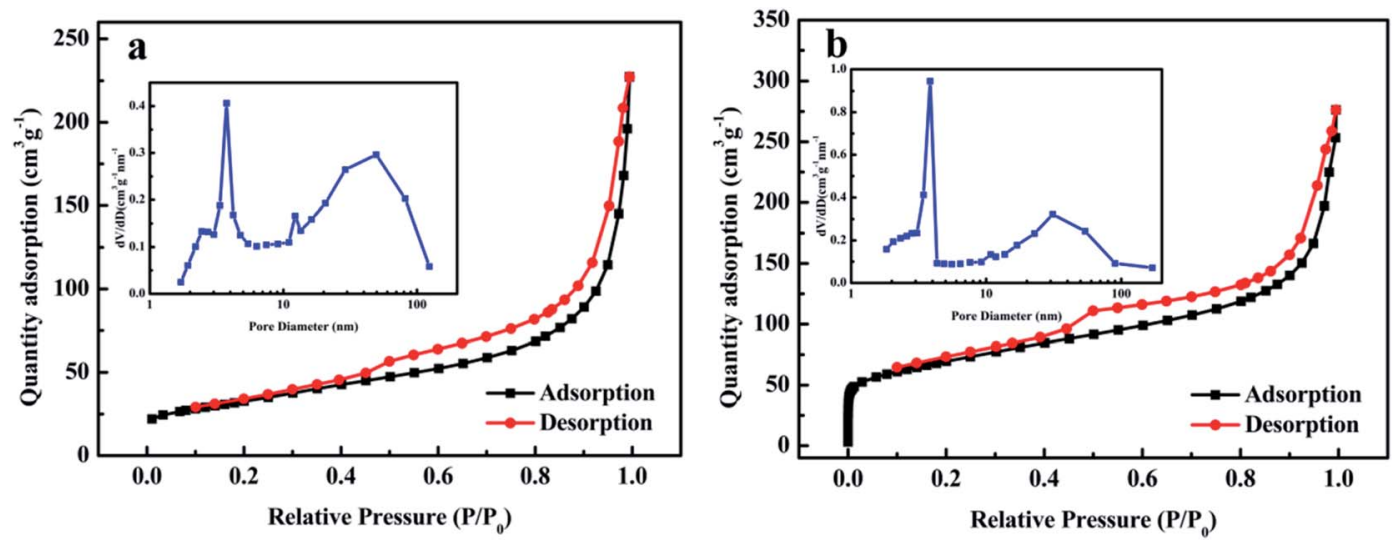

Fig. 3 BET adsorption-desorption curves and pore size distributions (inset) (a) GH and (b) NOGH-140. 

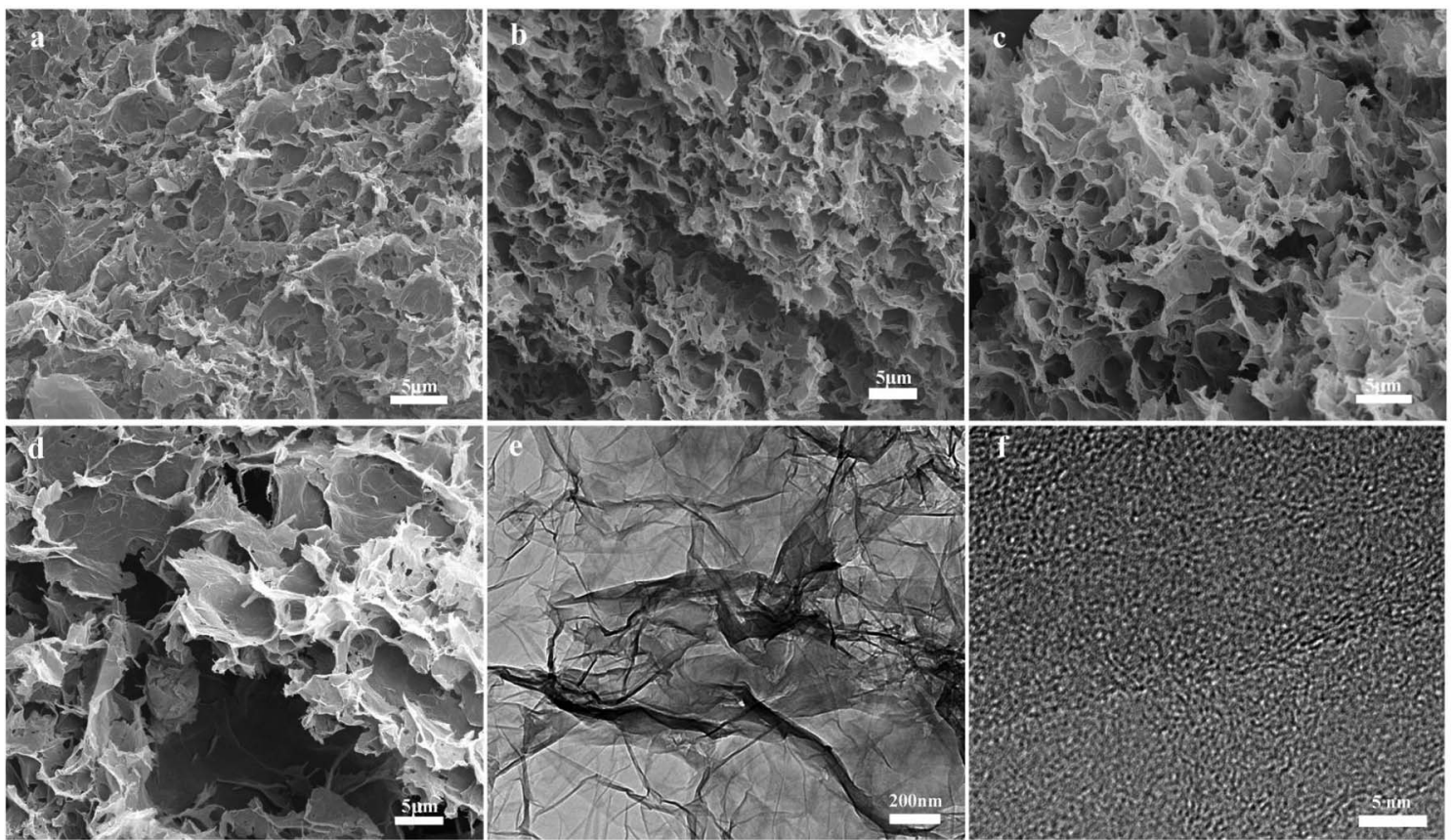

Fig. 4 SEM images of (a) GH, (b) NOGH-70, (c) NOGH-140, (d) NOGH-210 and TEM images of (e) NOGH-140, (f) HRTEM images of NOGH-140.

$\left(0.36 \mathrm{~cm}^{3} \mathrm{~g}^{-1}\right)$, demonstrating that the molecular chain of $n$ propylamine successfully prevented the restacking of graphene layers and increased the active specific surface area of NOGH140.

The morphology and microstructure of the freeze-dried samples were characterized using FESEM and TEM (Fig. 4). As presented in Fig. 4a, the agglomeration of graphene sheets in the GH sample is very serious, with few holes on its surface. Nevertheless, after the hydrothermal process with $n$-propylamine, the pore structure of the NOGHs sample become more prominent, showing a 3D porous network structure (Fig. $4 \mathrm{~b}-\mathrm{d}$ ). This can be attributed to the supporting effect of $n$-propylamine
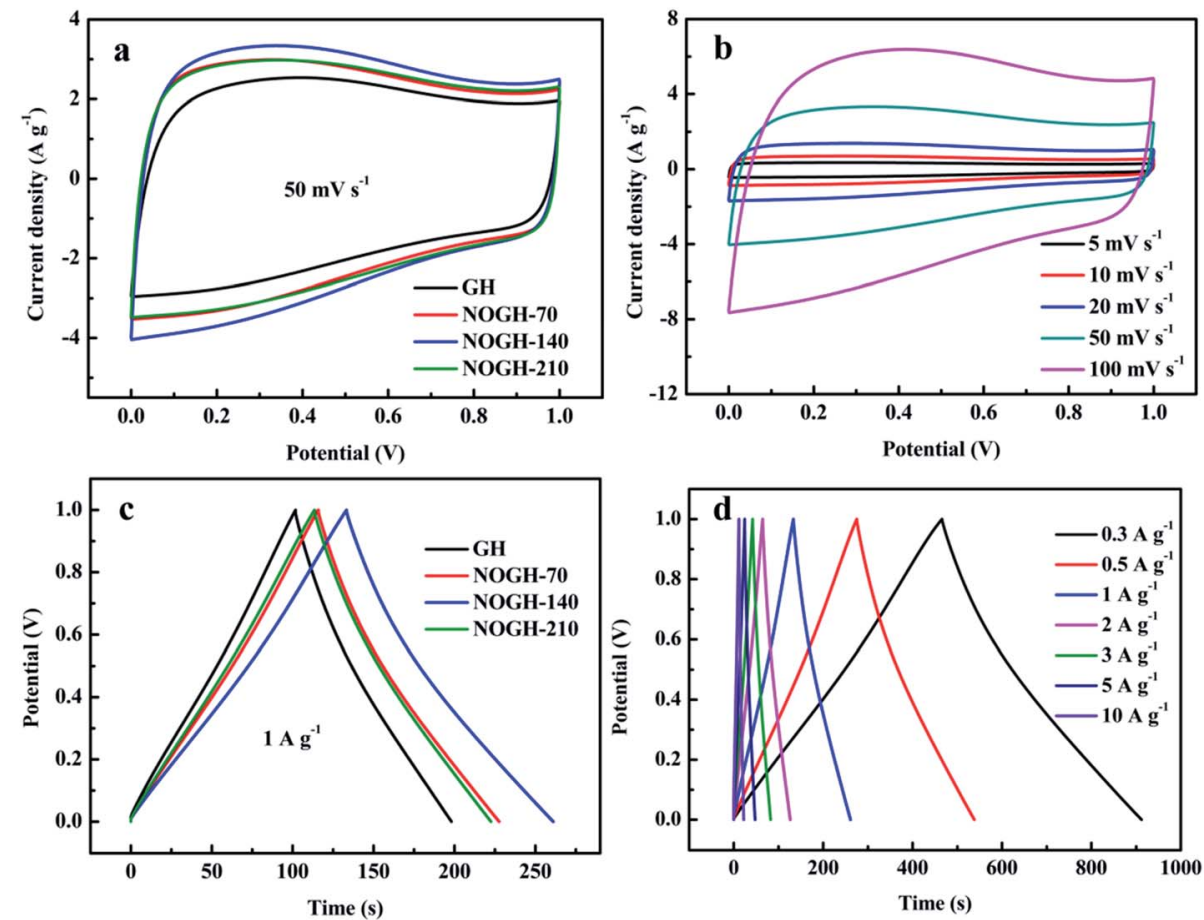

Fig. 5 Electrochemical performance of the symmetric supercapacitors: CV curves of (a) GH and NOGHs at $50 \mathrm{mV} \mathrm{s}{ }^{-1}$, (b) NOGH-140 at different scan rates and GCD curves of (c) GH and NOGHs at $1 \mathrm{~A} \mathrm{~g}^{-1}$, (d) NOGH-140 at different current densities. 
molecular chains on the adjacent graphene sheets. In addition, as the amount of $n$-propylamine increases, the $3 \mathrm{D}$ porous structure of the NOGHs samples becomes larger, and the structure of the graphene sheet becomes flatter and bigger. This is because, with the increase of $n$-propylamine dosage, the reaction system gradually becomes more alkaline, which will cause the agglomeration of graphene sheets and destroy its porous structure. Such a 3D porous network structure is beneficial to accelerate the contact, penetration and transport of the electrolyte ions in the electrode material, thereby reducing the diffusion resistance and improving its electrochemical performance. The TEM image manifests that NOGH-140 possesses a ripple configuration composed of few layers randomly stacked graphene sheets, further proving its 3D porous structure (Fig. 4e). As shown in Fig. 4f, the HRTEM image of NOGH-140 shows that there are obviously discontinuous and defects in the graphene sheets, which can be attributed to the lattice distortion caused by heteroatom doping. ${ }^{34}$

\subsection{Electrochemical studies}

In order to illustrate the potential for practical application of the as-prepared samples, the electrochemical property of the GH and NOGHs based binder-free symmetric supercapacitors were tested in $6 \mathrm{M} \mathrm{KOH}$. Fig. 5a displays the $\mathrm{CV}$ curves of $\mathrm{GH}$ and NOGHs at the scan rate of $50 \mathrm{mV} \mathrm{s}^{-1}$. Markedly, the $\mathrm{CV}$ curve of GH displays a nearly rectangular-like shape, denoting its EDLC property. On the contrary, NOGHs present a distorted CV loop with a broad hump located at around 0.1-0.8 V, which indicates that the concomitance of EDLC behaviour and pseudocapacitance behaviour. In addition, the integral area of NOGHs is obviously larger than that of $\mathrm{GH}$ at the same scan rate, implying the enhanced porous structure and abundant heteroatom functional groups are constructive to their capacitive property. As shown in Fig. 5b, NOGH-140 can maintain its curve shape even at a high scan rate of $100 \mathrm{mV} \mathrm{s}^{-1}$, which denotes its quick ion transport speed and excellent rate capability. ${ }^{35}$

The representative GCD curves of GH and NOGHs at $1 \mathrm{Ag}^{-1}$ are presented in Fig. 5c. Apparently, NOGHs based devices possess longer discharge time, further indicating their larger specific capacitance. Fig. 5d presents the GCD curves of NOGH140 at various current densities from 0.3 to $10 \mathrm{~A} \mathrm{~g}^{-1}$. From Fig. 5d, we can see that all the curves display a distorted triangular shape, revealing the combination of EDLC capacitance and pseudocapacitance. Furthermore, the NOGH-140 based symmetric supercapacitor presents a negligible IR drops even at $10 \mathrm{~A} \mathrm{~g}^{-1}$, confirming its good electrochemical reversibility and excellent rate capability. ${ }^{36}$ Fig. 6 a compares the $I R$ drop of $\mathrm{GH}$ and NOGHs samples at various current densities. It's worth noting that $\mathrm{GH}$ possesses bigger $I R$ drop in comparison with NOGHs, which can be assigned to the increase in electrical conductivity of the material caused by the restoring effect of graphitic $\mathrm{N}$ on the graphene sheet. The smaller $I R$ drop of NOGHs can reduce their internal resistance, ensure the integrity of their potential window, and improve their energy storage efficiency.

Fig. 6b illustrates the relationship of the specific capacitance against current densities in the assembled symmetric
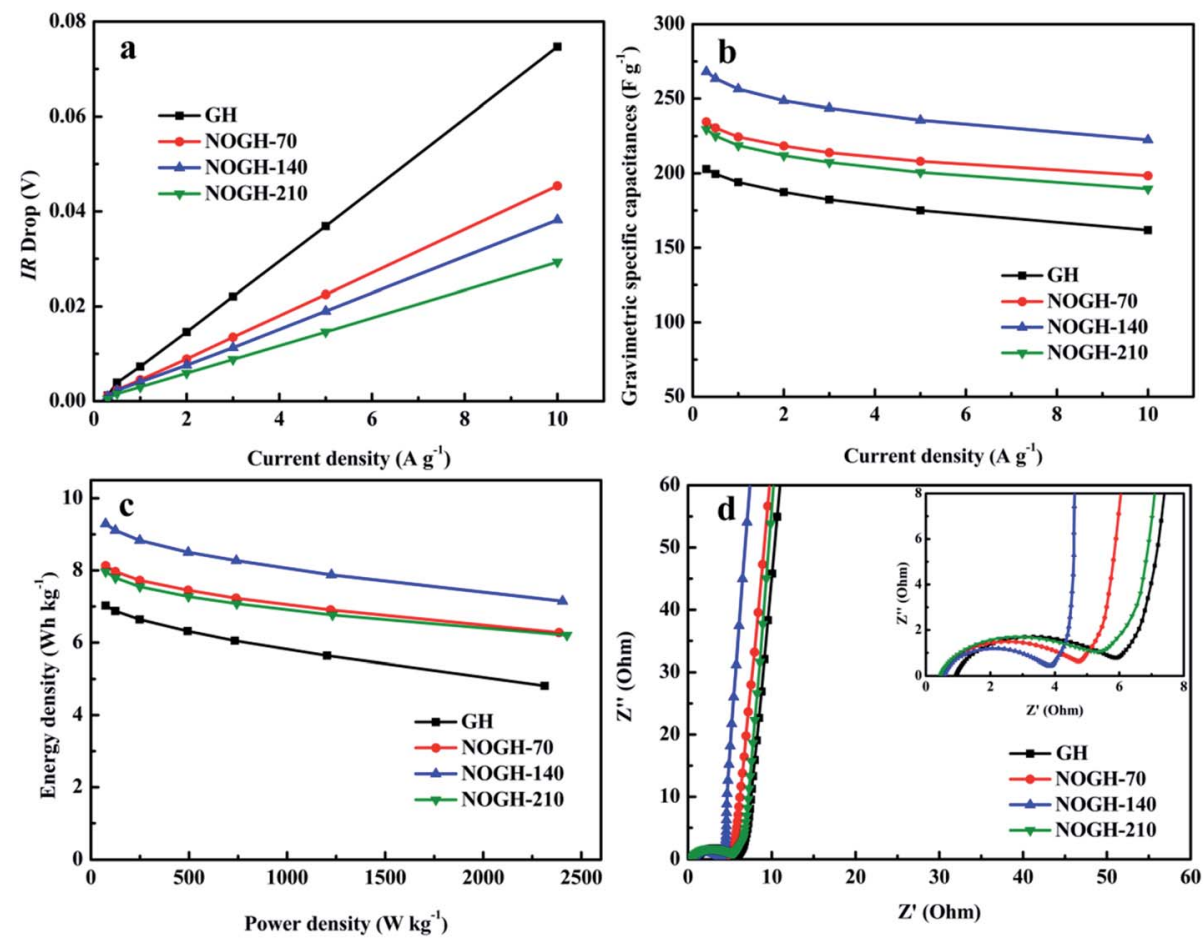

Fig. 6 (a) IR drop variation and (b) specific capacitances of GH and NOGHs at different current densities. (c) Ragone plots and (d) EIS results of GH and NOGHs. Inset in (d) shows the expanded high-frequency region of the plots. 
supercapacitors, directly revealing their rate capability. The NOGH-140 based symmetric supercapacitor delivers the specific capacitance of $268.1,263.5,256.5,248.6,243.7,235.7$, and $222.5 \mathrm{~F} \mathrm{~g}^{-1}$ at $0.3,0.5,1,2,3,5$ and $10 \mathrm{~A} \mathrm{~g}^{-1}$, which is superior to most previously reported heteroatom doped carbon materials (Table 3). At the same time, GH based device only shows 202.9, 199.6, 194.0, 187.4, 182.3, 175.1 and $161.8 \mathrm{~F} \mathrm{~g}^{-1}$ at the same test current densities. More importantly, the NOGH-140 based symmetric supercapacitor also displays better rate capability $(82.9 \%)$ compare to $\mathrm{GH}(79.7 \%)$, which can be attributed to their improved porous structure, smaller internal resistance and the synergistic effect of $\mathrm{N}$ and $\mathrm{O}$ functional groups. ${ }^{37}$

In order to determine the practical application prospect of the as-prepared samples, the Ragone plots of GH and NOGHs were obtained based on the GCD measurement (Fig. 6c). Noticeably, the NOGH-140 based symmetric supercapacitor presents an exceptional energy density of about $9.3 \mathrm{~W} \mathrm{~h} \mathrm{~kg}^{-1}$ at power density of $74.9 \mathrm{~W} \mathrm{~kg}^{-1}$ at a current density of $0.3 \mathrm{~A} \mathrm{~g}^{-1}$, which is superior to most previously reported carbon-based symmetric supercapacitors (Table 3 ). And the energy density can still reach up to $7.2 \mathrm{~W} \mathrm{~h} \mathrm{~kg}{ }^{-1}$ with the power density of $2404.5 \mathrm{~W} \mathrm{~kg}^{-1}$ at a high current density of $10 \mathrm{~A} \mathrm{~g}^{-1}$. Nevertheless, the GH based device can merely get an energy density of $7.0 \mathrm{~W} \mathrm{~h} \mathrm{~kg}^{-1}$ when the power density is $74.9 \mathrm{~W} \mathrm{~kg}^{-1}$ at a current density of $0.3 \mathrm{~A} \mathrm{~g}^{-1}$. The excellent energy density denotes that NOGHs samples can be employed as electrode materials for the commercial supercapacitors.

EIS technique was further used to investigate the internal resistance and the accessibility of electrolyte ions within the $\mathrm{GH}$ and NOGHs samples, as shown in Fig. 6d. The inclined line at low frequency region represents the charge storage behavior and diffusion process of the electrode materials. Clearly, NOGHs display larger phase angle than that of GH at low frequency region, confirming that they have better capacitive behaviors and smaller electrolyte ion diffusion resistance due to their improved porous structure and higher content of beneficial heteroatoms. ${ }^{43}$ In the high frequency region, the diameter of the semicircle at the real axis is response to the impedance on electrode/electrolyte interface. It is seen that NOGHs present smaller semicircle (charge transfer resistance), which is helpful to boost their charge storage capability. ${ }^{\mathbf{4 4 , 4 5}}$ Moreover, the intercept at extremely high frequency region is due to the internal resistance. In comparison with $\mathrm{GH}$, NOGHs exhibit smaller intercept, demonstrating their larger electric conductivity owing to the restoring of the conjugation of graphene sheet by $\mathrm{N}$ doping (inset in Fig. 6d). The EIS results reveal that the internal resistance and electrochemical kinetics of NOGHs have been significantly improved.

As long service life is the most parameter to assess the practicability of supercapacitors, the cycling performance of NOGH-140 was conducted using GCD measurement. As shown in Fig. 7, after 10000 GCD cycles at $10 \mathrm{~A} \mathrm{~g}^{-1}$, the NOGH-140 based binder-free symmetric supercapacitor can deliver a high specific capacitance of $226.5 \mathrm{~F} \mathrm{~g} \mathrm{~g}^{-1}$ (inset in Fig. 7). Its specific capacitance reaches $101.8 \%$ of the initial value, demonstrating its excellent long-term cycle stability. The excellent cycling performance indicates that the NOGH-140 based symmetric supercapacitor possesses a high quality of reversibility in the GCD cycle test, which can be ascribed to its good electric conductivity, 3D porous structure and superb reactivity of heteroatomic functional groups. These results suggest that NOGH-140 is suitable for practical applications in supercapacitors.

Electrochemical test results show that NOGH-140 has better supercapacitor performance than NOGH-70 and NOGH-210,

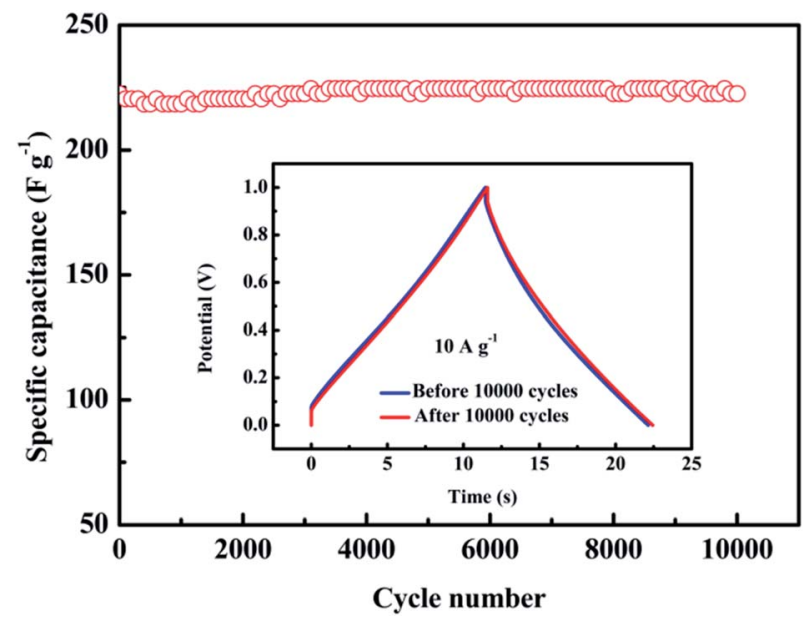

Fig. 7 Cycling stability of NOGH-140 at $10 \mathrm{~A} \mathrm{~g}^{-1}$ for $10000 \mathrm{GCD}$ cycles. Inset shows the GCD curves of NOGH-140 at $10 \mathrm{~A} \mathrm{~g}^{-1}$ before and after 10000 cycles.

Table 3 Electrochemical performances of different carbon-based electrodes in two-electrode system

\begin{tabular}{|c|c|c|c|c|c|c|}
\hline POGHs & $6 \mathrm{M} \mathrm{KOH}$ & $256.5\left(0.5 \mathrm{~A} \mathrm{~g}^{-1}\right)$ & 8.8 & $10 \mathrm{~A} \mathrm{~g}^{-1}$ & 10000 (100.7) & 12 \\
\hline $\mathrm{GH}$ & $5 \mathrm{M} \mathrm{KOH}$ & $165.0\left(1 \mathrm{~A} \mathrm{~g}^{-1}\right)$ & - & - & - & 38 \\
\hline AQSGH & $1 \mathrm{M} \mathrm{H}_{2} \mathrm{SO}_{4}$ & $258\left(0.3 \mathrm{~A} \mathrm{~g}^{-1}\right)$ & - & $10 \mathrm{~A} \mathrm{~g}^{-1}$ & $2000(>100)$ & 39 \\
\hline ERGO & $6 \mathrm{M} \mathrm{KOH}$ & $161.1\left(1 \mathrm{~A} \mathrm{~g}^{-1}\right)$ & 5.0 & $2 \mathrm{Ag}^{-1}$ & $10000(89.7)$ & 40 \\
\hline N-GH & $6 \mathrm{M} \mathrm{KOH}$ & $217.8\left(1 \mathrm{~A} \mathrm{~g}^{-1}\right)$ & - & $20 \mathrm{Ag}^{-1}$ & $1000(95.8)$ & 42 \\
\hline NOGHs & $6 \mathrm{M} \mathrm{KOH}$ & $268.1\left(0.3 \mathrm{~A} \mathrm{~g}^{-1}\right)$ & 9.3 & $10 \mathrm{~A} \mathrm{~g}^{-1}$ & $10000(101.8)$ & This work \\
\hline
\end{tabular}


which may be due to the following reasons: (1) the NOGH-140 sample has a lower content of epoxy functional groups and a higher $\mathrm{C} / \mathrm{O}$ ratio, which gives it a higher electrical conductivity. (2) In the hydrothermal reaction system, more n-propylamine tends to make the solution more alkaline, resulting in the agglomeration of graphene sheets, which will affect their EDLC performance. (3) The composition of surface heteroatom functional groups and good porous structure give NOGH-140 a small charge transfer resistance, which greatly improves its electrochemical performance.

\subsection{Discussion}

We believe that NOGHs samples can be used as supercapacitor electrode materials can be attributed to the following reasons:

(1) The synergistic coupling effect of $\mathrm{N}$ and $\mathrm{O}$ functional groups. Firstly, heteroatom doping can regulate the electronic structure of graphene materials by changing the charge distribution and spin density of carbon atoms, thereby significantly improving their electrochemical reaction activity. Based on the above characteristics, N/O coenriched graphene with two kinds of heteroatoms can further improve the electrochemical reaction activity of graphene materials by virtue of its synergistic coupling effect. Secondly, different $\mathrm{N}$ bonding configurations in NOGHs samples can greatly improve their energy storage properties. Among them, pyridinic $\mathrm{N}$ and pyrrolic $\mathrm{N}$ can produce plenty of pseudocapacitance by means of Faraday redox reactions, while graphitic $\mathrm{N}$ can improve the conductivity of the material and reduce its charge transfer resistance. In addition, compared with carbon atom, nitrogen atom have larger electronegativity, which can cause the polarization of carbon atoms in graphene sheets, thus facilitating the adsorption of electrolyte ions on the surface of the sample and improves its capacitive property. In NOGHs, the pseudocapacitance of different $\mathrm{N}$ bonding configurations can be generated under $6 \mathrm{M} \mathrm{KOH}$ solutions as follows: ${ }^{46,47}$

$$
\begin{gathered}
-\mathrm{C}-\mathrm{N}-\mathrm{C}+\mathrm{H}_{2} \mathrm{O}+\mathrm{e}^{-} \leftrightarrow-\mathrm{C}-\mathrm{NH}-\mathrm{C}+\mathrm{OH}^{-} \\
-\mathrm{C}=\mathrm{NH}+\mathrm{H}_{2} \mathrm{O}+2 \mathrm{e}^{-} \leftrightarrow-\mathrm{CH}-\mathrm{NHOH}
\end{gathered}
$$

Thirdly, the presence of abundant oxygen-containing functional groups in the NOGHs samples can increase the wettability of the material, thereby increasing their permeability and active specific surface area. More importantly, these oxygencontaining functional groups can provide large amounts of pseudocapacitances for the NOGHs samples through the following reactions: ${ }^{48}$

$$
\begin{gathered}
>\mathrm{C}-\mathrm{OH} \leftrightarrow>\mathrm{C}=\mathrm{O}+\mathrm{H}^{+}+\mathrm{e}^{-} \\
-\mathrm{COOH} \leftrightarrow-\mathrm{COO}^{-}+\mathrm{H}^{+}+\mathrm{e}^{-} \\
>\mathrm{C}=\mathrm{O}+\mathrm{e}^{-} \leftrightarrow>\mathrm{C}-\mathrm{O}^{-}
\end{gathered}
$$

(2) The enhanced 3D porous structure. The good 3D porous structure of NOGHs samples can be attributed to the introduction of $n$-propylamine molecular chains on graphene sheets. These molecular chains can act as physical spacers to restrain the agglomeration between the adjacent graphene sheets.

(3) Simple preparation method. Complex preparation methods and expensive use prices have always been the main reasons for limiting the practical application of graphene materials. In this work, we used the hydrothermal method to prepare graphene electrode materials at a relatively low temperature. This method has the advantages of low cost, low energy consumption, and easy to large-scale production. Most importantly, the preparation of graphene materials by this method can retain the oxygen-containing functional groups on the surface of the material as much as possible, which can not only increase the atomic utilization rate of the reaction system but also improve the electrochemical performance of the material.

In sum, we believe that NOGHs with excellent electrochemical performance and low cost can be used as electrode materials for supercapacitors.

\section{Conclusion}

In summary, NOGHs were effectively prepared by a simple hydrothermal approach with GO and $n$-propylamine as reactant. The results demonstrate that $n$-propylamine can be used as reductant, nitrogen dopant and structure regulator at the same time. Moreover, the molecular chain of $n$-propylamine can also be used as spacer to constrain the agglomeration of graphene sheets. By virtue of the synergistic coupling effect of $\mathrm{N}$ and $\mathrm{O}$ functional groups, 3D porous structure and high specific surface, the as-prepared NOGHs samples present excellent electrochemical properties in binder-free symmetric supercapacitors. The specific capacitance of the NOGH-140 based device is $268.1 \mathrm{~F} \mathrm{~g}^{-1}$ at $0.3 \mathrm{~A} \mathrm{~g}^{-1}$, and the capacitance retention can reach up to $82.9 \%$ at $10 \mathrm{~A} \mathrm{~g}^{-1}$, denoting an excellent rate capability. In addition, the assembled device also delivers high energy density of $9.3 \mathrm{~W} \mathrm{~h} \mathrm{~kg}^{-1}$ at $74.9 \mathrm{~W} \mathrm{~kg}^{-1}$ and maintains $7.2 \mathrm{~W} \mathrm{~h} \mathrm{~kg}^{-1}$ at $2404.5 \mathrm{~W} \mathrm{~kg}^{-1}$. Furthermore, NOGHs show a superb cycling performance (101.8\%) after 10000 GCD cycles at $10 \mathrm{~A} \mathrm{~g}^{-1}$. These results prove that NOGHs have the potential to be applied in electrochemical energy storage device.

\section{Conflicts of interest}

There are no conflicts to declare.

\section{Acknowledgements}

This work was supported by the National Natural Science Foundation of China (No. 52072191), Heilongjiang Provincial Natural Science Foundation of China (No. LH2020E126), and the Fundamental Research Fund of Heilongjiang Provincial University (No. 135509204). 


\section{Notes and references}

1 R. Zhou, Z. Yang, J. Z. Xu and G. Z. Cao, Coord. Chem. Rev., 2018, 374, 279-313.

2 J. T. Zhou, X. T. Wei, J. Zhu, X. Yang, H. H. Niu, L. Wan, P. Jiang, J. Z. Xu, R. Zhou and G. Z. Cao, Sci. China Mater., 2020, 63, 1151-1162.

3 W. W Zhong, W. G. Tu, Z. P. Wang, Z. P. Lin, A. J Xu, X. F. Ye, D. C. Chen and B. B. Xiao, J. Energy Chem., 2020, 51, 280-284. 4 W. W. Zhong, S. J. Shen, M. He, D. Wang, Z. P. Wang, Z. P. Lin, W. G. Tu and J. G. Yu, Appl. Catal., B, 2019, 258, 117967.

5 W. W. Zhong, X. H. Huang, Y. Lin, Y. Q. Cao and Z. P. Wang, J. Energy Chem., 2021, 58, 386-390.

6 Z. Y. Wu, Y. N. Wang, L. Zhang, L. Jiang, W. C. Tian, C. L. Cai, J. Price, Q. F. Gu and L. F. Hu, ACS Appl. Energy Mater., 2020, 3, 3919-3927.

7 L. Jiang, Z. Y. Wu, Y. N. Wang, W. C. Tian, Z. Y. Yi, C. L. Cai, Y. C. Jiang and L. F. Hu, ACS Nano, 2019, 13, 10376-10385.

8 Z. Y. Wu, L. Jiang, W. C. Tian, Y. N. Wang, Y. C. Jiang, Q. F. Gu and L. F. Hu, Adv. Energy Mater., 2019, 9, 1900111.

9 Y. C. Jiang, Y. Song, Y. M. Li, W. C. Tian, Z. C. Pan, P. Y. Yang, Y. S. Li, Q. F. Gu and L. F. Hu, ACS Appl. Mater. Interfaces, 2017, 9, 37645-37654.

10 P. Y. Yang, Y. C. Jiang, Z. C. Pan, W. C. Tian, L. Jiang and L. F. Hu, Adv. Energy Mater., 2018, 8, 1801392.

11 R. Ye, J. Cai, Y. Pan, X. R. Qiao and W. Sun, Diamond Relat. Mater., 2020, 105, 107816.

12 Y. Zhang, S. Fan, S. H. Li, Y. Song and G. W. Wen, J. Mater. Sci., 2020, 55, 12214-12231.

13 Y. C. Jiang, L. Jiang, Z. Y. Wu, P. Y. Yang, H. T. Zhang, Z. C. Pan and L. F. Hu, J. Mater. Chem. A, 2018, 6, 1630816315.

14 B. Rani and N. K. Sahu, Diamond Relat. Mater., 2020, 108, 107978.

15 Y. Zhang, G. W. Wen, S. Fan, W. H. Ma, S. H. Li, T. Wu, Z. C. Yu and B. R. Zhao, Electrochim. Acta, 2019, 313, 59-69.

16 Y. Zhang, G. W. Wen, S. Fan, W. H. Ma, S. H. Li, T. Wu, Z. C. Yu and B. R. Zhao, Int. J. Hydrogen Energy, 2019, 44, 23726-23740.

17 Y. Zhang, G. W. Wen, S. Fan, Y. Y. Chu, S. H. Li, B. Y. Xu and J. Zhang, J. Power Sources, 2019, 435, 226799.

18 M. Herrera-Alonso, A. A. Abdala, M. J. McAllister, I. A. Aksay and R. K. Prud'homme, Langmuir, 2007, 23(21), 1064410649.

19 V. H. Luan, H. N. Tien, L. T. Hoa, N. T. M. Hien, E. S. Oh, J. S. Chung, E. J. Kim, W. M. Choi, B. S. Kong and S. H. Hur, J. Mater. Chem. A, 2013, 1, 208-211.

20 H. Hu, Z. B. Zhao, W. B. Wan, Y. Gogotsi and J. S. Qiu, Adv. Mater., 2013, 25, 2219-2223.

21 N. I. Kovtyukhova, P. J. Ollivier, B. R. Martin, T. E. Mallouk, S. A. Chizhik, E. V. Buzaneva and A. D. Gorchinskiy, Chem. Mater., 1999, 11, 771-778.

22 Y. Z. Feng, B. Wang, X. W. Li, Y. S. Ye, J. M. Ma, C. T. Liu, X. P. Zhou and X. L. Xie, Carbon, 2019, 146, 650-659.
23 Y. J. Chen, L. Sun, Z. E. Liu, Y. Y. Jiang and K. L. Zhuo, Mater. Chem. Phys., 2019, 238, 121932.

24 K. N. Kudin, B. Ozbas, H. C. Schniepp, R. K. Prud'homme, I. A. Aksay and R. Car, Nano Lett., 2008, 8, 36-41.

25 H. L. Cao, X. F. Zhou, Z. H. Qin and Z. P. Liu, Carbon, 2013, 56, 218-223.

26 L. Y. Ma, J. Liu, S. Lv, Q. Zhou, X. Y. Shen, S. B. Mo and H. Tong, J. Mater. Chem. A, 2019, 7, 7591-7603.

27 A. Sikdar, P. Dutta, A. Majumdar, M. Borah and U. N. Maiti, Electrochim. Acta, 2020, 332, 135492.

28 Z. Ramezani and H. Dehghani, Int. J. Hydrogen Energy, 2019, 44, 13613-13622.

29 Z. P. Wang, B. Xiao, Z. P. Lin, S. J. Shen, A. J. Xu, Z. X. Du, Y. C. Chen and W. W. Zhong, J. Energy Chem., 2021, 54, 510-518.

30 H. F. Yang, F. H. Li, C. S. Shan, D. X. Han, Q. X. Zhang, L. Niu and A. Ivaska, J. Mater. Chem., 2009, 19, 4632-4638.

31 Y. H. Sun, D. M. Zhu, Z. F. Liang, Y. X. Zhao, W. F. Tian, X. C. Ren, J. Wang, X. Y. Li, Y. Gao, W. Wen, Y. B. Huang, X. L. Li and R. Z. Tai, Carbon, 2020, 167, 685-695.

32 J. L. Yang, Z. C. Ju, Y. Jiang, Z. Xing, B. J. Xi, J. K. Feng and S. L. Xiong, Adv. Mater., 2018, 30, 1700104.

33 Q. Li, A. Y. Bai, Z. C. Xue, Y. Zheng and H. Sun, Electrochim. Acta, 2020, 362, 137223.

34 A. G. Kannan, J. X. Zhao, S. G. Jo, Y. S. Kang and D. W. Kim, J. Mater. Chem. A, 2014, 2, 12232-12239.

35 X. Wang, Z. H. Qin, X. Q. Yang, Q. Chen and Z. Lin, Diamond Relat. Mater., 2020, 108, 107995.

36 C. J. Zhao, Y. X. Huang, C. H. Zhao, X. X. Shao and Z. Q. Zhu, Electrochim. Acta, 2018, 291, 287-296.

37 L. L. Zhang, H. X. Chen, X. Y. Lu, Y. Wang, L. L. Tan, D. P. Sui and W. Qi, Appl. Surf. Sci., 2020, 529, 147022.

38 Y. X. Xu, K. X. Sheng, C. Li and G. Q. Shi, ACS Nano, 2010, 4, 4324-4330.

39 Q. Wu, Y. Q. Sun, H. Bai and G. Q. Shi, Phys. Chem. Chem. Phys., 2011, 13, 11193-11198.

40 V. H. Pham and J. H. Dickerson, J. Phys. Chem. C, 2016, 120, 5353-5360.

41 T. T. Li, N. Li, J. W. Liu, K. Cai, M. F. Foda, X. M. Lei and H. Y. Han, Nanoscale, 2015, 7, 659-669.

42 H. Xin, D. W. He, Y. S. Wang, W. Zhao and X. Du, RSC Adv., 2015, 5, 8044-8049.

43 W. W. Zhong, Z. P. Wang, N. Gao, L. A. Huang, Z. P. Lin, Y. P. Liu, F. Q. Meng, J. Deng, S. F. Jin, Q. H. Zhang and L. Gu, Angew. Chem., Int. Ed., 2020, 59, 22743-22748.

44 Z. P. Wang, Z. P. Lin, J. Deng, S. J. Shen, F. Q. Meng, J. T. Zhang, Q. H. Zhang, W. W. Zhong and L. Gu, Adv. Energy Mater., 2020, 11, 2003023.

45 W. W. Zhong, B. B. Xiao, Z. P. Lin, Z. P. Wang, L. A. Huang, S. J. Shen, Q. H. Zhang and L. Gu, Adv. Mater., 2021, 33, 2007894.

46 N. K. Rotte, V. Naresh, S. Muduli, V. Reddy, V. V. S. Srikanth and S. K. Martha, Electrochim. Acta, 2020, 363, 137209.

47 L. Sun, L. Wang, C. G. Tian, T. X. Tan, Y. Xie, K. Y. Shi, M. T. Li and H. G. Fu, RSC Adv., 2012, 2, 4498-4506.

48 H. Y. Liu, H. H. Song, X. H. Chen, S. Zhang, J. S. Zhou and Z. K. Ma, J. Power Sources, 2015, 285, 303-309. 